\title{
Ionospheric perturbations observed by the GPS following the December 26th, 2004 Sumatra-Andaman earthquake
}

\author{
Ashish DasGupta ${ }^{1,2}$, Aditi Das ${ }^{1}$, Debrup Hui ${ }^{2}$, Kalyan Kumar Bandyopadhyay ${ }^{3}$, and M. R. Sivaraman ${ }^{3}$ \\ ${ }^{1}$ Institute of RadioPhysics and Electronics, University of Calcutta, Kolkata, India-700009 \\ ${ }^{2}$ S. K. Mitra Center for Research in Space Environment, University of Calcutta, Kolkata, India-700009 \\ ${ }^{3}$ Space Application Center, Ahmedabad, India-380015
}

(Received June 30, 2005; Revised December 5, 2005; Accepted December 12, 2005; Online published February 17, 2006)

\begin{abstract}
Using the Total Electron Content (TEC) data recorded by the GPS receiver network, installed under the GPS and Geo Augmented Navigation (GAGAN) program, ionospheric electron content on the day of the great Sumatra-Andaman earthquake of December 26, 2004 was examined. A significant perturbation of 1.5 to 2 TEC units over a smooth variation of TEC in the morning hours was observed within 45 minutes of the quake at stations situated near the east coast of the Indian subcontinent. The disturbance was found to propagate northwestward with its origin situated about $2^{\circ}$ northeast of the quake epicenter. Possible coupling mechanism of the crustal movement and the ionosphere are discussed.
\end{abstract}

Key words: Earthquake, tsunami, ionospheric response, atmospheric gravity wave, Total Electron Content, seismoelectric effect.

\section{Introduction}

On December 26, 2004, at 00:58:53 UT, a strong earthquake $\left(M_{w}=9.15\right)$ originated in the Indian Ocean just north of Simeulue island, off the western coast of northern Sumatra, Indonesia (Park et al., 2005). This earthquake generated Tsunami that was among the deadliest disasters in modern history . The hypocenter of the quake was $3.31^{\circ} \mathrm{N}$, $95.85^{\circ} \mathrm{E}$, some $160 \mathrm{~km}$ west of Sumatra at a depth of $30 \mathrm{~km}$ below the mean sea level. The epicenter of the quake was $3.29^{\circ} \mathrm{N}$ and $95.94^{\circ} \mathrm{E}$. An estimated $1200 \mathrm{~km}$ of faultline slipped about 15 meter along the subduction zone, where the Indian Plate dives under the Burma Plate. Due to the sideways movement between the plates, the seabed is estimated to have risen by several meters, displacing an estimated $30 \mathrm{~km}^{3}$ of water and triggering Tsunami waves.

Near surface sources causing large vertical displacement of the earth surface during strong earthquakes are often known to excite the atmospheric infrasonic waves (e.g. Blanc, 1985) that propagate upward with increasing amplitude. Ionospheric disturbances induced by severe earthquakes have been reported by, Yuen et al. (1969), Blanc (1985), Tanaka et al. (1984) and Wolcott et al. (1984), Calais and Minister, (1995), Hobara and Parrot, (2005), Artru et al. (2005). The measurement of ionospheric Total Electronic Content (TEC) by using Global Positioning System (GPS) transmission have been used by Calais and Minister, (1995) to show the ionospheric response to the Northridge earthquake (Southern California) on January 17, $1994\left(M_{w}=6.7\right)$. The present paper reports a preliminary study on ionospheric perturbations observed subsequent to

Copyright (c) The Society of Geomagnetism and Earth, Planetary and Space Sciences (SGEPSS); The Seismological Society of Japan; The Volcanological Society of Japan; The Geodetic Society of Japan; The Japanese Society for Planetary Sciences; TERRAPUB the recent catastrophic December 26, 2004 earthquake.

\section{Data}

To implement Satellite Based Augmentation System (SBAS) of GPS in India, Indian Space Research Organisation (ISRO) in collaboration with Airport Authority of India (AAI) has set up 20 GPS receivers at the different airports all over India. The dual frequency GPS receivers, operating at L1 (1575.42 MHz) and L2 (1227.6 MHz) frequencies measure the Total Electron Content along the slant ray path (STEC). The data contains STEC, as well as the azimuth, elevation, satellite PRN Number, time etc at 1 minute interval in RINEX format (Mannucci et al., 1997). By measuring the carrier phase at the two frequencies the STEC is obtained (Klobuchar, 1996) along the path from satellite to the receiver. The $350 \mathrm{~km}$ subionospheric point of the satellite signal is calculated from the station's location, azimuth and elevation data.

\section{Results}

The STEC over the whole day of December 26, 2004, for all visible GPS satellites at elevation angles above $15^{\circ}$ are available for the stations- Vishakhapatnam $\left(17.72^{\circ} \mathrm{N}, 83.22^{\circ} \mathrm{E}\right)$, Kolkata $\left(22.64^{\circ} \mathrm{N}, 88.44^{\circ} \mathrm{E}\right)$, Aizwal $\left(23.83^{\circ} \mathrm{N}, 92.62^{\circ} \mathrm{E}\right)$, Raipur $\left(21.18^{\circ} \mathrm{N}, 81.73^{\circ} \mathrm{E}\right)$, Hyderabad $\left(17.44^{\circ} \mathrm{N}, 78.47^{\circ} \mathrm{E}\right)$, Bagdogra $\left(26.68^{\circ} \mathrm{N}, 88.32^{\circ} \mathrm{E}\right)$, Guwahati $\left(26.12^{\circ} \mathrm{N}, 91.59^{\circ} \mathrm{E}\right)$, Mumbai $\left(19.09^{\circ} \mathrm{N}, 72.85^{\circ} \mathrm{E}\right)$, Bangalore $\left(12.95^{\circ} \mathrm{N}, 76.68^{\circ} \mathrm{E}\right)$, Trivandrum $\left(8.47^{\circ} \mathrm{N}, 76.91^{\circ} \mathrm{E}\right)$ and Agatti $\left(10.23^{\circ} \mathrm{N}, 72.18^{\circ} \mathrm{E}\right)$. Among these stations, Vishakhapatnam, Kolkata, Aizwal, Hyderabad, Raipur, Bagdogra and Guwahati recorded prominent purturbations of STEC on four different satellites (Sv3, Sv13, Sv19 and Sv23) links in the morning hours around 1:36-1:45 UT for December 26, 2004, nearly one hour after the earthquake. 

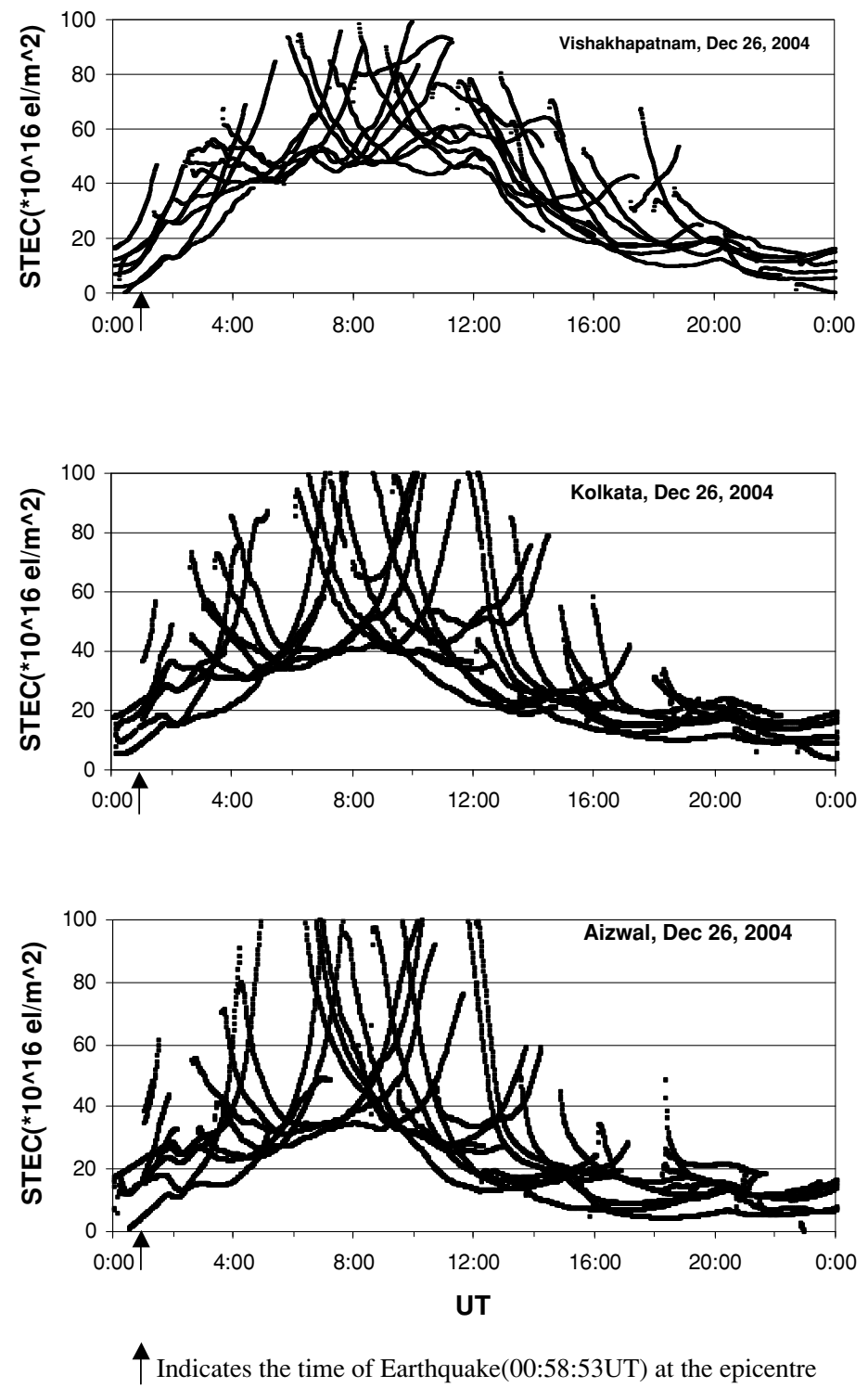

Fig. 1. The diurnal variation of STEC at Vishakhapatnam, Kolkata and Aizwal on December 26, 2004. The different curves show TEC along the slant path for different satellites. The large scatter of the plots may be attributed to the differing lookangles of the GPS satellites and transmitter and receiver biases. The low value of TEC (approximately 0 TEC unit) around 00:00 UT may be receiver bias error. The diurnal minimum normally lies in the 2-10 TEC unit range in the presunrise hour. The arrow indicates the commencement of the earthquake.

The other stations mentioned earlier did not record any such prominent variation of STEC. The enhancement is high in the stations in the eastern part of India such as Vishakhapatnam, Kolkata and Aizwal. This perturbation also shows time delays that increase with the distance from the epicenter. Figure 1 describes the diurnal STEC plot for the same date from Vishakhapatnam, Kolkata and Aizwal including all visible satellites. The large variability of the curves, particularly during the daytime is related to differing look angles of the GPS satellites and transmitter and receiver clock biases, among other factors. The electron content during post sunrise hours normally shows a smooth rising trend. On December 26, 2004 a prominent perturbation superimposed on the gradual increase was observed.

In Fig. 2, we compare STEC for December 26, 2004, the day of the quake with those of (i) the average value of STEC for December 20-25, 2004 (ii) STEC for December
25,2004 , the day prior to the earthquake, and (iii) STEC for December 27, 2004, the day after the quake, for Sv3 from different stations which observed the perturbations of STEC during the morning hours. The figures clearly bring out the above feature- the peak of the STEC perturbations on December 26 is well distinguished from the other curves. To determine the amplitude of perturbation of STEC, the moving average of STEC is obtained over 90 minutes interval and then by subtracting this average STEC from the original data the deviation of STEC is obtained. Figure 3 shows the STEC deviation obtained from the stations Kolkata, Vishakhapatnam and Aizwal. The amplitude of maximum perturbation is 1.90 at 1:38 UT in Kolkata whereas it is 1.79 at 1:38 UT in Vishakhapatnam and 2.18 at 1:40 UT in Aizwal, respectively. The deviation has a period of 1 hour 17 minute at Kolkata and 1 hour 6 minute at Aizwal respectively. The other satellites Sv13, Sv19 and Sv23, observed 

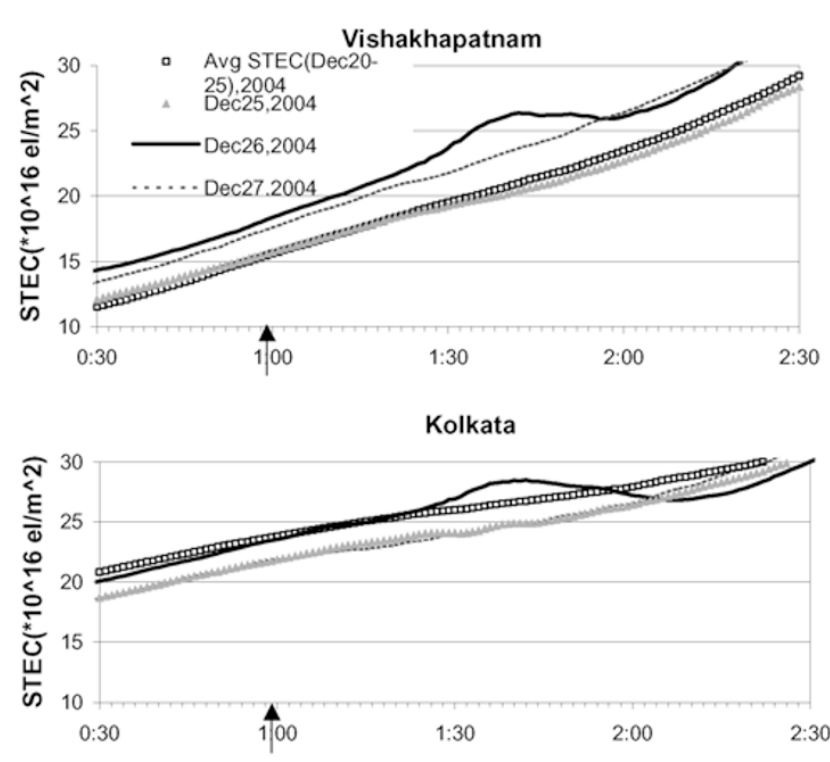

Aizwal

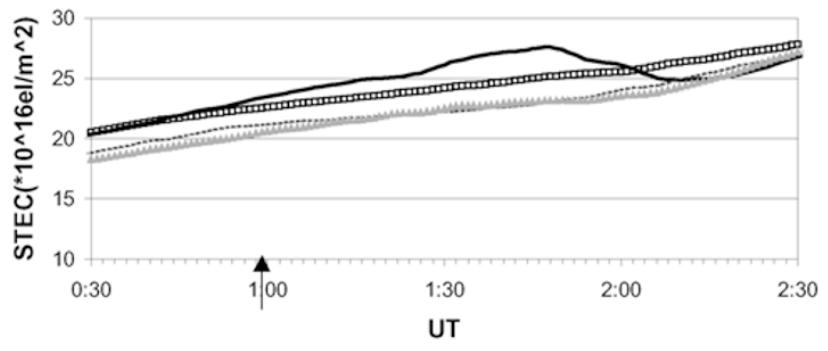

Indicates the time of Earthquake(00:58:53UT) at the epicentre
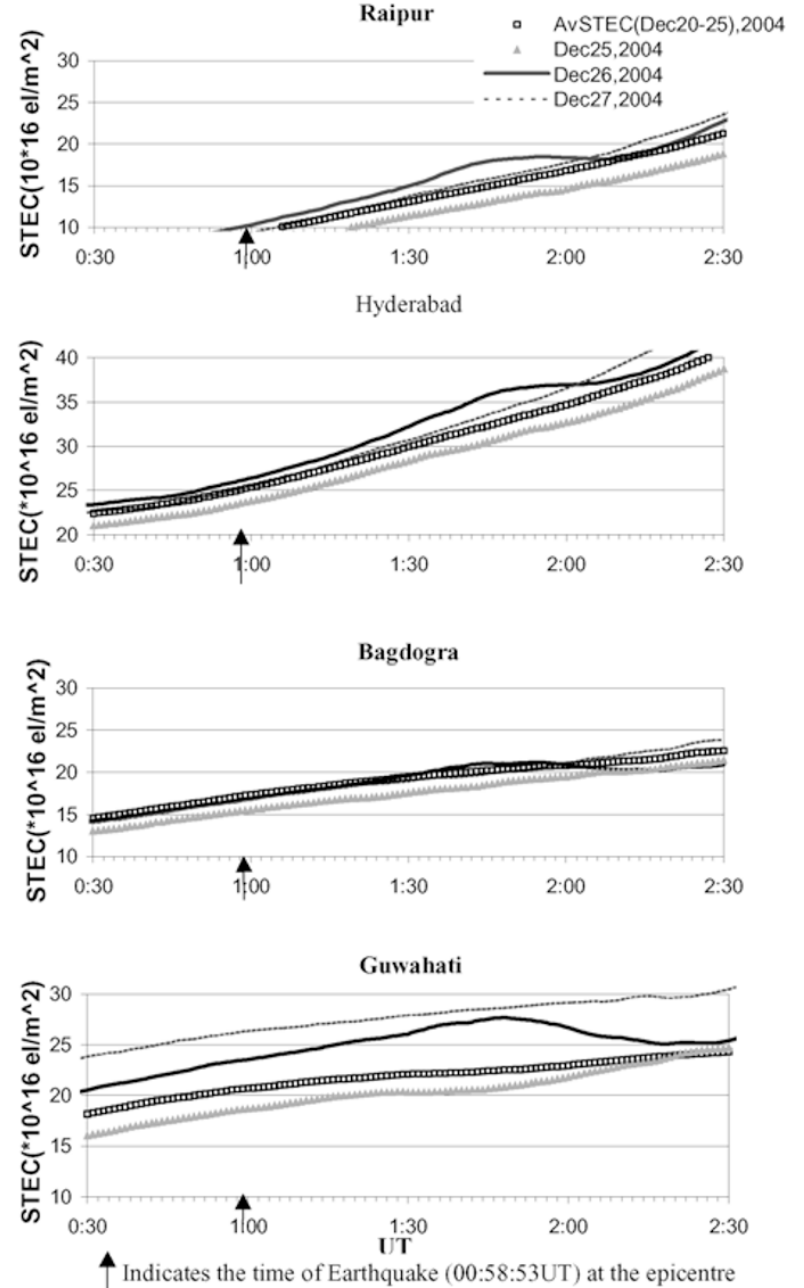

Fig. 2. Variation of STEC at the seven stations: Vishakhapatnam $\left(17.72^{\circ} \mathrm{N}, 83.22^{\circ} \mathrm{E}\right)$, Hyderabad $\left(17.44^{\circ} \mathrm{N}, 78.47^{\circ} \mathrm{E}\right), \mathrm{Raipur}^{\circ}\left(21.18^{\circ} \mathrm{N}, 81.73^{\circ} \mathrm{E}\right)$, Kolkata $\left(22.64^{\circ} \mathrm{N}, 88.44^{\circ} \mathrm{E}\right)$, Bagdogra $\left(26.68^{\circ} \mathrm{N}, 88.32^{\circ} \mathrm{E}\right)$, Guwahati $\left(26.12^{\circ} \mathrm{N}, 91.59^{\circ} \mathrm{E}\right)$, and Aizwal $\left(23.83^{\circ} \mathrm{N}, 92.62^{\circ} \mathrm{E}\right)$ on satellite $\mathrm{Sv} 3$ on an expanded scale in the morning hour. Comparison of December 26th data with those of December 25th (one day before the quake) and December 27 th (one day after the quake) and five day average before the earthquake clearly shows the ionospheric perturbation at stations near the eastern coast of Indian subcontinent. The arrow indicates the commencement of the earthquake.

during the morning hours also showed similar features.

The $350 \mathrm{~km}$ subionospheric tracks of the satellite Sv3 are shown in the Fig. 4 from the seven GPS stations where the perturbation of STEC is recorded. The number beside each track corresponds to the station from which it is observed. The phase velocity of the disturbance has been determined by velocity triangulation method by combination of different stations like Hyderabad-VishakhapatnamKolkata, Raipur-Kolkata-Vishakhapatnam and BagdograAizwal-Guwahati. Then the phase velocity of the disturbance and its direction with respect to true north is calculated for the middle station of the combinations given above. The phase velocitiy at Vishakhapatnam is found to be $639.38 \mathrm{~m} / \mathrm{sec}(2301.768 \mathrm{~km} / \mathrm{hr})$ at $62.59^{\circ}$ northwest of true north and $688.8 \mathrm{~m} / \mathrm{sec}(2479.68 \mathrm{~km} / \mathrm{hr})$ at $19.51^{\circ}$ northwest of true north at Aizwal. The propagation velocity of ionospheric disturbances is in fair agreement with values reported by Calais and Minister (1995) and corresponds to medium to large scale traveling ionospheric disturbances. When plotted, it is found that these disturbances seem to emanate from a narrow zone within $2^{\circ}$ northeast from the epicenter of the said earthquake.

\section{Discussions}

The paper is a preliminary report of the ionospheric effects observed on the Slant Total Electron Content along the ray path from different stations near the east coast of the Indian subcontinent subsequent to the Sumatra-Andaman earthquake of December 26, 2004. A significant perturbation of the TEC (1.5-2 units of TEC) approximately 45 minutes after the earthquake was recorded on a number of satellites from stations like Vishakhapatnam, Hyderabad, Raipur, Kolkata, Bagdogra, Guwahati, and Aizwal. No such perturbation was recorded in TEC plot at stations in the northern and western parts of the country. The observed ionospheric variation is thus regional in nature. The devastating Tsunami waves of amplitude 2.4 meters hit the Indian south-east coast around Vishakhapatnam (latitude: $17.72^{\circ} \mathrm{N}$, longitude: $83.22^{\circ} \mathrm{E}$ geographic) at $03: 35$ UT. The observed ionospheric perturbation at Vishakhapatnam and Kolkata was recorded about 2 hours earlier than the Tsunami surfaces waves reaching Indian's southeastern coast.

Although ionospheric perturbations like the one reported in this paper are attributed to seismic activities, the mecha- 

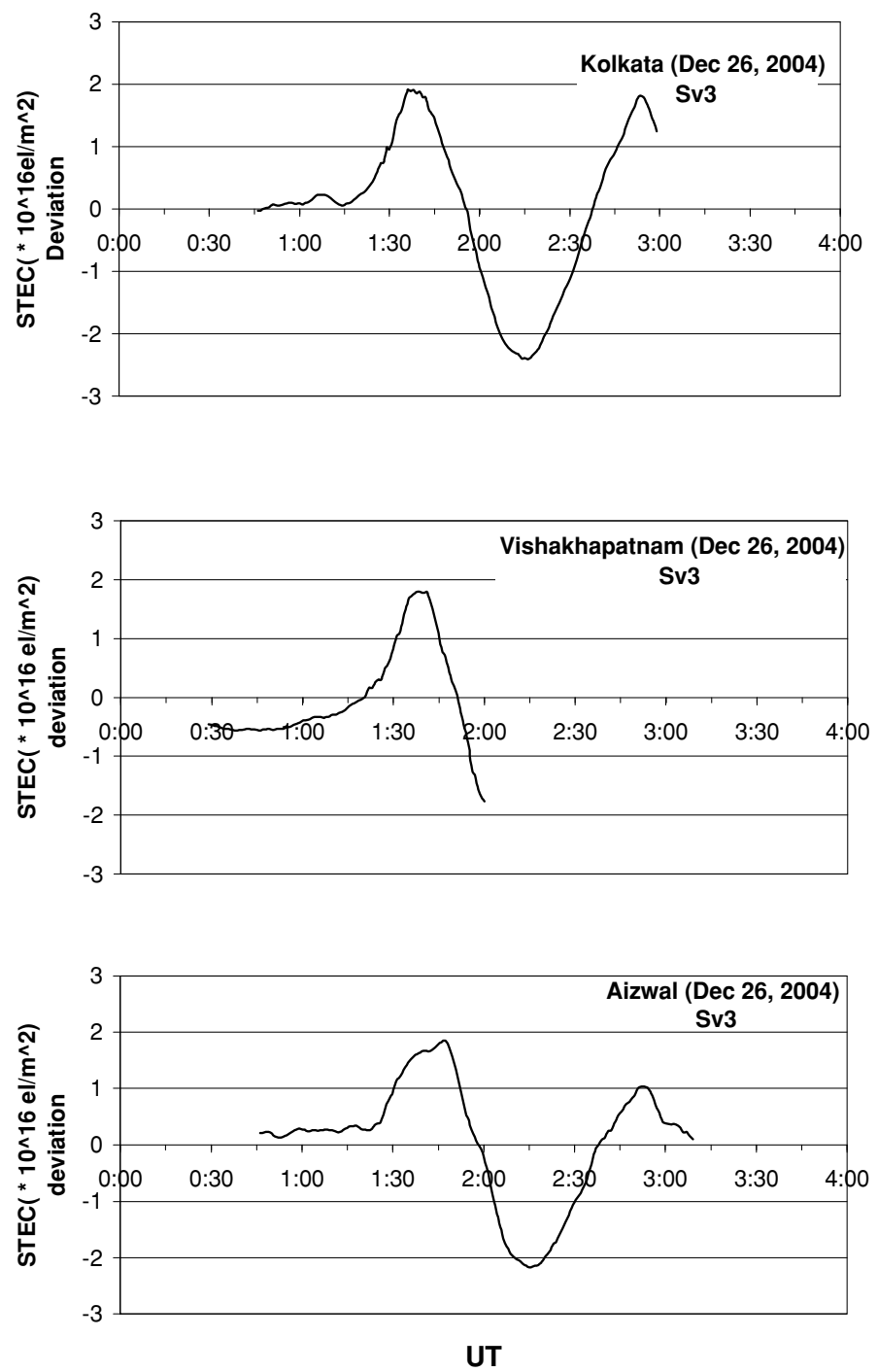

Fig. 3. Deviation of STEC from the 90 minutes moving average plot in the morning hours with satellite Sv3.

nism of coupling of the ionosphere to earthquake is yet to be fully understood. In the earliest formulation based on coupled atmospheric gravity waves, proposed by Hines (1960), Peltier and Hines (1976), a vertical displacement of the sea surface due to a Tsunami can be a source of gravity wave in the atmosphere. The surface gravity wave propagates obliquely upward with an increase in the wave amplitude due to the exponential decrease of the atmospheric density and manifests as Travelling Ionospheric Disturbances (TID) in the upper atmosphere (Clark et al., 1971; Yeh and Liu, 1972). Kirchengast (1996) discussed general features of TID and estimated that amplitude of the ionization perturbations due to TID is upto $10 \%$ of the background. Some of the TIDs may be related to Tsunami and/or earthquake, although he did not specify only Tsunami induced TID.

Seismic activity may also induce electro magnetic perturbation, which may lead to variation of ionospheric parameters (Hobara and Parrot, 2005; Pulinet et al., 1994, 2003). Radon, Hydrogen and Helium emanating from the earthquake region may change the electrodynamic property of the ionosphere and generate atmospheric gravity waves. The main electrodynamic effect of seismic activitiy induced gas emanation is a large scale modification of the vertical atmospheric electric field in the ground layer of the atmosphere. The vertical electric field subsequently reaches into the ionosphere and transform into horizontal field (Kim et al., 1994).

A large scale seismogenic electric field may modulate the daily variation in the normal solar controlled electric field at ionospheric height. The present observations are made in a region where the electrodynamic drift of the ionosphere is very effective in producing equatorial anomaly by the 'Fountain Effect' (Martyn, 1955; Hanson and Mofett, 1966) during daytime. The perturbation in TEC presented in this paper occurs in the post sunrise hours. The electric field is westward during the night and returns to eastward direction around local sunrise. The equatorial anomaly phenomenon was yet to be developed when the perturbations were observed. The epicenter of the earthquake lies south of the magnetic equator $\left(10^{\circ} \mathrm{N}\right.$ geographic latitude) and the fault line slip extends approximately north-south over 1200 $\mathrm{km}$. The magnetic equator crosses the line around $10^{\circ} \mathrm{N}$ geographic latitude in the $90^{\circ} \mathrm{E}$ longitude zone. Any seismoelectric modulation enhancing the eastward electric field 


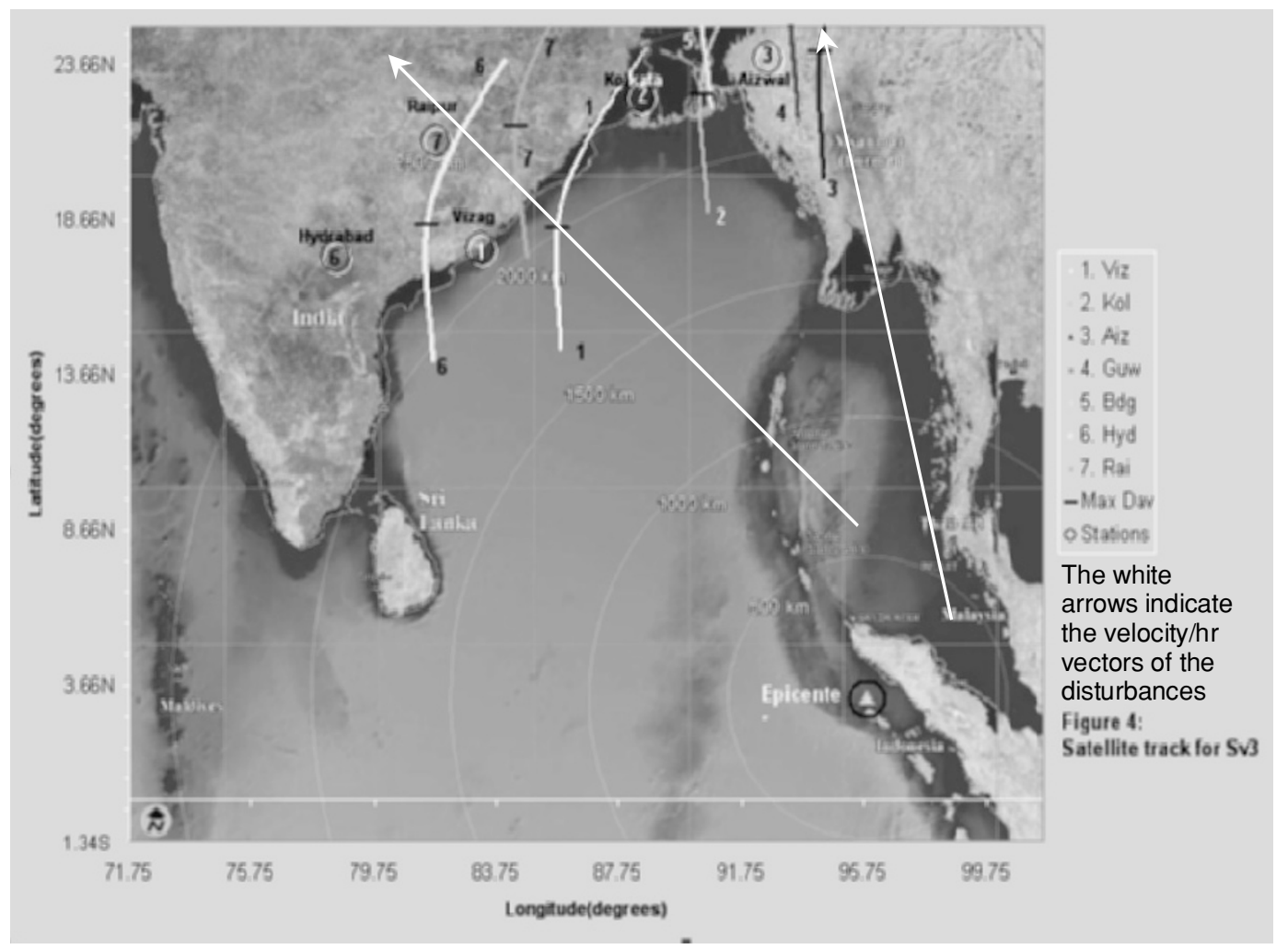

Fig. 4. Sub-ionospheric tracks of GPS Sv3 observed from different stations. The horizontal black breaks correspond to maximum STEC perturbation. The distance from the epicenter is also indicated. The white arrows on the position of maximum perturbation from Vishakhapatnam and Aizwal indicate the velocity vectors. The velocities are in $\mathrm{km} / \mathrm{hr}$. Source of the map: UNOSAT (http://unosat.web.cern.ch/unosat/).

over the magnetic equator may result in plasma influx to off-equatorial locations by upward electrodynamic drift at the equator and diffusion along the magnetic field lines to off-equatorial locations. The redistribution of ionizations would normally take 1-2 hours to reach off-equatorial locations like Vishakhapatnam and Kolkata. The observed TEC perturbation could be distinctly identified as it occurred in the local time interval of 00-09 hour LT, when the variation is smooth and regular. Otherwise, it would be difficult to isolate such fluctuations from the large perturbation normally encountered in the TEC plots in the equatorial region for a major part of the day.

In order to establish any definitive cause-effect relationship of severe seismic activity event and ionospheric response numerical models based on physical processes and the severity of seismic activity has to be developed. The purpose of this paper is to report a perturbation of TEC observed with the GPS TEC network of the Indian Satellite Based Augmentation System (GAGAN) in India. A more detailed analysis of the data is underway and will be published in due course.

Acknowledgments. A part of this research work reported in this paper was supported by Indian Space Research Organisation (ISRO) at the S. K. Mitra Center for Research in Space Environment of Calcutta University through research projects. The authors are indebted to Space Application Center (SAC), Ahmadabad, India for supplying the GAGAN GPS TEC data and www.wikipedia.org for information on Tsunami. The authors thank Dr. Otsuka and another Referee for suggesting improvement of the manuscript.

\section{References}

Artru, J., V. Ducic, H. Kanamori, and P. Lognonne, Ionospheric detection of gravity waves induced by tsunamis, Geophys. J. Inst., 160, 840-848, 2005.

Blanc, E., Observations in the upper atmosphere of infrasonic waves from natural or artificial sources: a summary, Ann. Geophys., 3, 673-668, 1985.

Calais, E. and J. B. Minister, GPS detection of ionospheric perturbations following the January 17, 1994, Northridge earthquake, Geophys. Res. Lett., 22, 1045-1048, 1995.

Clark, R. M., K. C. Yeh, and C. H. Liu, Interaction of internal gravity waves with the ionospheric f2-layer, Phys. Earth Planet. Inter., 33, 1567-1576, 1971.

Hanson, W. B. and R. J. Moffett, Ionization transport in the equatorial F region, J. Geophys. Res., 71, 5559, 1966.

Hines, C. O., Internal atmospheric gravity waves at ionospheric heights, Canadian J. of Phys., 38, 1441-1481, 1960.

Hobara, Y. and M. Parrot, Ionospheric perturbations linked to a very powerful seismic event, J. Atmos. Sol-Terr. Phys., 67, 677-685, 2005.

Kim, V. P., V. V. Hegai, and P. V. Illich-Svitych, On the possible precursor of earthquakes, Fizika Zemli, 3, 37, 1994.

Kirchengast, G., Elucidation of the physics of the gravity wave-TID relationship with the aid of theoretical simulations, J. Geophys. Res., 101, 13353-13368, 1996.

Klobuchar, J. A., cited in Global Positioning System: Theory and Applications, Volume I, edited by B. W. Parkinson and J. J. Spilker, Jr., American Institute of Aeronautics ans Astronautics. Inc., 485 pp., 1996.

Mannucci, A. J., C. M. Ho, X. Pi, B. D. Wilson, and U. J. Lindqwister, Group delay and phase advance due to ionospheric total electron content, in Proceedings of the workshop on Space Weather Effects on propagation of Navigation and Communication Signals, edited by E. J. Fremouw, pp. 117-139, COMSAT corp., Bethesda, Md., 1997.

Martyn, D. F., Physics of the Ionosphere, The Physical Society, London, 254 pp., 1955.

Park, J., R. A. Anderson, R. Butter, T. Lay, and D. Simpson, Global Seismographic Network records: the great Sumatra-Andaman Earthquake, Transaction American Geophysical Union, 86, 2005. 
Peltier, W. R. and C. O. Hines, On the possible detection of tsunamis by a monitoring of the ionosphere, J. Geophys. Res., 81, 1995-2000, 1976.

Pulinets, S. A., A. D. Legenka, and V. M. Alekseev, Pre-earthquake ionospheric effects and their possible mechanisms, in Dusty and Dirty Plasmas. Noise and Chaos in Space and in the Laboratory, pp. 545-556, edited by H. Kikuchi, Plenum Press, New York, 1994.

Pulinets, S. A., A. D. Legenka, T. V. Gaivoronskaya, and V. Kh. Depuev, Main phenomenological features of ionospheric precursors of strong earthquakes, J. Atmos. Sol-Terr. Phys., 65, 1337-1347, 2003.

Tanaka, T., T. Tchinose, T. Okusawa, T. Shibata, Y. Sato, C. Nagasawa, and T. Ogawa, HF Doppler observations of acoustic waves exhibited by the Urakawa-Oki earthquake on 21 March, 1982, J. Atmos. Terr. Phys., 46, 233-245, 1984.
Wolcott, J. H., D. J. Simons, D. D. Lee, and R. A. Nelson, Observations of an ionospheric perturbation arising from the Coalinga earthquake of May 2, 1983, J. Geophys. Res., 89, 6835-6839, 1984.

Yeh, K. C. and C. H. Liu, Theory of Ionospheric Waves, pp. 402-418, Academic Press, New York, 1972.

Yuen, P. C., P. F. Weaver, and R. K. Suzuki, Continuous traveling coupling between seismic waves and the ionosphere evident in May 1968 Japan earthquake data, J. Geophys. Res., 74, 2256-2264, 1969.

A. DasGupta (e-mail: adg1bkpr@hotmail.com), A. Das, D. Hui, K. K. Bandyopadhyay, and M. R. Sivaraman 